\title{
Actitudes hacia la inmigración y compromiso igualitario en Europa
}

\author{
Antonio MARTín ARTILES \\ Institut Estudis del Treball. Universitat Autònoma de Barcelona \\ antonio.martin@uab.es \\ Guglielmo MEARDI \\ Warwick University. Reino Unido \\ guglielmo.meardi@wbs.ac.uk
}

Recibido: 13-01-2012

Aceptado: 16-10-2012

\begin{abstract}
Resumen
Las actitudes de los ciudadanos europeos hacia la inmigración son restrictivas. Las actitudes restrictivas están relacionadas con la tasa de desempleo y el riesgo de pobreza, así como con la competencia por los recursos de empleo y bienestar. Las políticas nacionales de protección social contribuyen a reducir la hostilidad hacia la inmigración porque reduce el riesgo de pobreza y las desigualdades sociales. Sin embargo, la heterogeneidad étnica y racial dificulta el "compromiso igualitario" imprescindible para la sostenibilidad del Estado del Bienestar. Los sindicatos fuertes y las políticas de protección social contribuyen a la integración de la inmigración (Suecia y Noruega). Por el contrario, los sindicatos débiles, las desigualdades sociales, el desempleo, el riesgo de pobreza y la débil protección social contribuyen al desarrollo de actitudes negativas hacia la inmigración (Grecia, Hungría). La futura sostenibilidad del bienestar dependerá de la participación de la inmigración como fuerza política.
\end{abstract}

Palabras clave: Actitudes; opiniones; igualdad; solidaridad; inmigración; Estado Bienestar

\section{Attitudes towards immigration and egalitarian compromises in Europe}

\begin{abstract}
Attitudes of European citizens towards immigrants are restrictive. Restrictive attitudes are related to the unemployment rate and the risk of poverty as well as competition for jobs and welfare resources. National policies of social protection help reduce hostility to immigration because it reduces the risk of poverty and social inequality. However, ethnic and racial heterogeneity hamper "egalitarian commitment" essential for the sustainability of the welfare state. Strong unions and social protection policies contribute to the integration of immigrants (Sweden and Norway). By contrast, weak unions, social inequalities, unemployment, the risk of poverty and weak social protection contribute to the development of ne gative attitudes towards immigration (Greece, Hungary). The future sustainability of welfare depends on the participation of immigration as a political force.
\end{abstract}

Key words: Attitudes; opinion; equality; solidarity; immigration; Welfare 


\section{Referencia normalizada}

Martín Artiles, A., Meardi, G. (2013). "Actitudes hacia la inmigración y compromiso igualitario en Europa”. Política y Sociedad, Vol.50, Núm. 2: 629-656

Sumario: Introducción; 1.Estado de la cuestión; 2.Análisis descriptivo de las actitudes. 3.Modelos de bienestar y compromiso igualitario; 4.Políticas de integración y actitudes; Conclusiones. Bibliografía

\section{Introducción}

En la Unión Europea hay un cierto consenso político en considerar necesaria la inmigración de trabajadores de fuera de Europa a causa del descenso de la natalidad y del creciente envejecimiento de la población (European Commission, 2007, 2008; Comisión Europea, 2011a y 2011b). Incluso hay analistas que hablan de "crisis demográfica" (Schierup, et. a. 2006). Como justificación de la necesidad de inmigración este hecho fue reconocido en el Consejo de Tampere en 1999: "Los flujos duraderos de inmigrantes en el transcurso de los próximos decenios pueden ayudar a cubrir las necesidades actuales y futuras de los mercados laborales europeos" (Comisión Europea 2003:3). El Consejo de Tampere pidió explícitamente "una política más decidida que debería encaminarse a conceder a los nacionales de terceros países que residan legalmente derechos y obligaciones comparables a los de los ciudadanos de la Unión" (Comisión Europea 2003:5, véase Directivas 2000/43/CE y 2000/78/CE ambas relativas a la igualdad de trato de las personas independientemente de su origen racial o étnico y el Reglamento CE $\mathrm{n}^{\circ}$ 859/2003 en materia de igualdad de trato en Seguridad Social). Otra referencia obligada es la aprobación por parte del Consejo de Ministros de Justicia y Asuntos de Interior el 19 de noviembre de 2004 de los "Principios Comunes Básicos sobre Integración", uno de cuyos puntos se refiere al acceso de los inmigrantes a las instituciones, a los bienes y servicios públicos y privados en las mismas condiciones que los ciudadanos nacionales y sin discriminaciones, lo que es un requisito básico para su integración (Cachón, 2008). Estas decisiones se enmarcan en la lógica de los llamados "valores universalistas" (Schwartz, 2007, 2011), que incluye ideas como equidad, justicia social y solidaridad (Rodríguez Monter, 2009).

Empero la inmigración se han interpretado como un "problema" y una "carga" porque contribuye a diluir los lazos de cohesión del triángulo "Ciudadanía, Estado y Nación" (Zapata-Barrero, 2001) y a la solidaridad necesaria para sostener al Estado del Bienestar (Habermas, 2000; Schierup, et al. 2006; Mau, Burkhardt, 2009). La crisis de la solidaridad está asociada a la heterogeneidad étnica, racial y cultural, así como a la débil participación política y sindical de los inmigrantes.

El objetivo de este artículo es analizar los factores contextuales relacionados con la opinión pública y las actitudes hacia la inmigración. Los factores contextuales como la tasa de desempleo, la tasa de inmigración y el riesgo de pobreza parecen estar asociados hipotéticamente con la competencia por los recursos de empleo y 
bienestar y con las actitudes negativas hacia la inmigración. Por el contrario, otros factores contextuales como las prestaciones por desempleo, el gasto en exclusión social, el gasto en protección social por habitante y las políticas de integración parecen mitigar las desigualdades sociales, lo que favorece la formación de actitudes tolerantes y solidarias hacia la inmigración. En la literatura especializada se ha venido debatiendo recientemente la importancia que tienen los valores relacionados con el "compromiso igualitario" como expresión solidaria de la cultura política europea (Schwartz, 2007, 2011; Gouveia, Ross, 2000; Rodriguez Monter, 2009, entre otros). Estos aspectos relativos a la solidaridad son apenas incipientes en la literatura, lo que justifica esta exploración sobre los valores, opiniones y actitudes de los ciudadanos europeos.

Este artículo se divide en cuatro secciones. En la primera abordamos el estado de la cuestión del debate teórico en relación a las variables que están asociadas a las actitudes. En la segunda sección describimos las actitudes hacia la entrada de inmigrantes y la actitud sobre el acceso de los inmigrantes a los derechos sociales, para ello hemos analizado la Encuesta Social Europea (ESE) de los años 2002, 2008 y 2010. En tercer lugar, abordaremos las correlaciones entre los modelos de bienestar, las actitudes y el contexto (para lo cual analizamos variables proporcionadas por Eurostat sobre desempleo, inmigración, riesgo de pobreza, desigualdad, gasto en protección social y protección por desempleo). Y, en cuarto lugar, abordamos la relación entre las políticas de integración social y las actitudes a partir del Índice Migrant Integration Policy III (Mipex, 2010). Finalmente apuntamos algunas conclusiones sobre los desafíos que representan la inmigración para la cohesión social y la sostenibilidad del Bienestar.

\section{Estado de la cuestión}

El estudio de las actitudes de los ciudadanos en relación al acceso de la inmigración a los derechos sociales se puede clasificar en tres tipos de explicaciones. En primer lugar, la competencia por los escasos recursos de empleo entre nativos e inmigrantes. En segundo lugar, por la competencia por los escasos recursos de bienestar (sanidad, educación y servicios sociales), así como por el balance entre la demanda de servicios y la contribución de los inmigrantes a las arcas del Estado. Y, en tercer lugar, la potencial pérdida de legitimidad del sistema de protección social a tenor de la creciente heterogeneidad de la población (Moreno, 2007).

\subsection{Competencia por los recursos de empleo}

En primer lugar, una de las explicaciones sobre la formación de las opiniones y actitudes restrictivas hacia la inmigración se ha venido asociando a la competencia por el empleo en el mercado de trabajo. El flujo inmigratorio ha comportado una modificación en el tamaño y la composición de la fuerza de trabajo (Saxton, Benson, 
2003; Card, et al. 2005; Feltzer, 2011), lo que ha sido un factor influyente en la precarización del empleo. En los segmentos de empleo donde se inserta la inmigración las condiciones de trabajo (salarios, jornada laboral, seguridad e higienes, etc.) han tendido a deteriorarse (Mayda, 2006; Miguélez, Recio, 2008), o bien ha comportado el aumento del empleo irregular y la economía sumergida (Reyneri, 2006), lo que actúa como una forma de dumping social porque "quema" las condiciones de trabajo, fragmenta el tejido asociativo, dificulta la acción colectiva y debilita la posición negociadora de los comités de empresa y de los sindicatos (González, 2008; Pajares, Jubany, 2011). Por consiguiente, aquellos que están en los segmentos de empleo más precarios, empleos temporales, bajas cualificaciones profesionales, bajos salarios y los desempleados, entre otros, suelen tener actitudes restrictivas y negativas hacia la entrada de inmigrantes.

\subsection{Competencia por los recursos de bienestar}

El segundo tipo de explicaciones trata la competencia por los escasos recursos de bienestar. Para algunos analistas (Schierup, et. al. 2006; Moreno, 2007), el "efecto llamada" del Estado del Bienestar estimula la afluencia de la inmigración irregular, el reagrupamiento familiar y la demanda de servicios asistenciales, lo que está asociado a la generación de opiniones negativas sobre el acceso de los inmigrantes a los derechos sociales.

Algunos estudios han argumentado que hay una de atracción de la inmigración asociada a las oportunidades de bienestar que ofrecen los Estados, de modo que ésta se concentra en aquellos Estados Nacionales que ofrecen mejores servicios sociales (Schierup, et. al. 2006). En dichos Estados se concentra especialmente la inmigración recién llegada, lo que se relaciona con las políticas sociales: éstas afectan a la percepción de rentas y a la maximización del beneficio esperado. La discusión de que los inmigrantes reciben más de lo que aportan a la economía nacional, o bien que éstos son los mayores beneficiarios de los programas de ayudas sociales ya ha sido explorada en la literatura (Schierup, et. al. 2006; Moreno, 2007; Banting; Kymilcka, 2008). El "efecto llamada" ha sido muy discutido y cuestionado, uno de los aspectos que nos interesa es precisamente contemplar la opinión de la ciudadanía europea sobre el acceso de los inmigrantes a los servicios y derechos sociales. Sin embargo, hipotéticamente las actitudes pueden variar según los contextos nacionales del bienestar, como son la tasa de desempleo, las prestaciones y subsidios por desempleo, el riesgo de pobreza, el gasto en exclusión social y el gasto social. Las desigualdades sociales, la competencia por los recursos de bienestar y la demanda de prestaciones por desempleo, subsidios y servicios asistenciales constituyen otro grupo de factores explicativos del recelo hacia la inmigración. La crisis económica, el desempleo, la irregularidad en la situación legal y las escasas prestaciones sociales devengadas de empleos precarios han arrojado a un considerable número de inmigrantes a los límites de la pobreza y de la exclusión social, espe- 
cialmente en los países del Sur de Europa (véase Reyneri, 2006; Miguélez, Recio, 2008, Cea D'Ancona, Vallés, 2010, entre otros).

Por el contrario, la corrección de las desigualdades sociales mediante políticas redistributivas de bienestar parece haber contribuido a $\mathrm{m}$ itigar las asimetrías y desigualdades que genera el mercado de trabajo. En este sentido se ha estudiado cómo las pensiones por desempleo, la reducción del riesgo de pobreza y exclusión social han tendido a amortiguar las tensiones de la competencia por los recursos de bienestar entre autóctonos e inmigrantes (Mayda, 2006; Morissen, 2008; Mau; Burkhardt 2009, entre otros).

\subsection{Multiculturalismo y erosión de la legitimidad del sistema de bienestar}

La tercera explicación sobre las actitudes hacia la inmigración aborda la relación entre la legitimidad del sistema de protección social y la creciente heterogeneidad de la población. El argumento que sostiene esta línea explicativa es que la inmigración reduce el apoyo de los nativos al Estado del Bienestar. Por un lado, las clases medias "huyen" de los servicios públicos porque en los lugares donde se concentra la inmigración se deteriora la calidad de los servicios sociales, lo que provoca una creciente desafección hacia el sistema de protección social y estimula la opción por el mercado como proveedor de servicios (Moreno, 2007).

Por otro lado, algunos estudios sociológicos (Banting; Kymlicka, 2008) han analizado los conflictos derivados de la diversidad racial y étnica, la discriminación de las minorías, la erosión de las relaciones interpersonales, la confianza, la fragmentación de la solidaridad social y la crisis de las coaliciones políticas que sostienen al Estado del Bienestar. En este sentido se ha explorado la idea de que aquellos países que tienen un mayor multiculturalismo han empeorado más las prestaciones del Estado del Bienestar que aquellos países que tienen un menor multiculturalismo: la homogeneidad racial y étnica del Estado-Nación contribuye a sostener la identidad y la solidaridad (Habermas, 2000). Por el contrario, las minorías étnicas y raciales dificultan la formación de coaliciones políticas para la defensa del Bienestar. Este es un problema creciente en Europa a tenor del aumento de los flujos inmigratorios en las últimas décadas. En cierto modo estamos ante el "dilema de la racialización" de las relaciones sociales en muchos países europeos. Dicha "racialización" tiene una importante similitud con el llamado "dilema americano de raza, clase y democracia" (Schierup, et. al. 2006:3-5). La diversidad étnica y racial ha hecho históricamente difícil la construcción de un Estado del Bienestar robusto en Estados Unidos. En contrapunto, los países que han tenido una homogeneidad racial o bien han tenido una escasa inmigración han tenido más fácil la construcción del Estado del Bienestar, y han podido formar sindicatos potentes, como especialmente los países del llamado neocorporatismo escandinavo. Este modelo de bienestar cuenta con altas tasas de afiliación sindical y fuerte presencia institucional de los sindicatos, lo que ha sido fundamental para la construcción de los Estados de Bienestar (Ferrara, 2005; Menz, 2005; Magnusson, et. al. 2008) 
En las últimas décadas, según señala Ferrara (2005), la aceleración de la integración económica europea (al mismo tiempo que ha aumentado el flujo inmigratorio) ha comportado crecientes tensiones étnicas y raciales en el mercado de trabajo. En otras palabras, las tensiones reflejan la dificultad para sostener cohesionadas las fuerzas políticas que han sustentado el "compromiso igualitario" en muchos países europeos. Para algunos analistas (Banting; Kymilca, 2008) la adopción de políticas inmigratorias abiertas facilita la movilidad de la fuerza de trabajo y la capacidad de lo ajuste en el mercado laboral (Schierup, et. al. 2006); pero la contrapartida ha sido una fragmentación en la composición de la clase trabajadora y la segmentación del mercado de trabajo: ello dificulta la representación de los sindicatos y de los partidos políticos valedores del Estado del Bienestar. En otras palabras, comporta una crisis de representación para los sindicatos y las coaliciones políticas de centroizquierda. En este sentido el multiculturalismo podría entenderse, según Banting y Kymilca (2008), como una deliberada política neoliberal para debilitar a los sindicatos, flexibilizar el mercado de trabajo y deslegitimar al Estado de Bienestar.

En contrapunto, otros autores sostienen que el reto que plantea la inmigración es la integración social (Ferrara, 2005; Castles, 2006; Schierup, et at. 2006). Para algunos analistas los valores culturales del país de acogida tienen una importante capacidad explicativa en la aceptación o el rechazo de los inmigrantes, como han demostrado recientemente, entre otros, el estudio de Rodríguez Monter (2009), apoyados en los estudios seminales de Schwartz. Los mencionados autores coinciden en que los países europeos conceden más importancia al "compromiso igualitario" que Norteamérica. Este compromiso se expresa en valores normativos como la igualdad, la justicia social, el bienestar de los otros y la tolerancia (Gouveia, Ross, 2000; Schwartz, 2007), lo que podría estar asociado con opiniones universalistas y con actitudes algo más favorables, tolerantes y predispuestas al reconocimiento de los derechos sociales de los inmigrantes.

Desde la perspectiva de los valores ideológico-políticos, algunos estudios (Saxton y Benson, 2003; Citrin et al. 2005; Ceobeanu, Escandell, 2010, entre otros) han puesto al descubierto el papel que juega los valores ideológicos y la identificación política en las actitudes favorables o restrictivas hacia la inmigración. Una distinción habitual es la orientación del voto en el espectro izquierda-derecha y las actitudes favorables y restrictivas hacia la inmigración. Por ejemplo, estos aspectos han sido analizados por Innerarity y Acha (2010) en el ámbito europeo y muestran como los partidos de extrema derecha tienen un discurso focalizado en actitudes antiinmigratorias y anti-universalistas que les lleva a rechazar el multiculturalismo. Para estos grupos políticos la inmigración es vista como "un problema", de ahí la creciente "politización de la inmigración" que entra a formar parte de los temas de la agenda política en los medios de comunicación y en el debate parlamentario (Balch, 2010). En pocas palabras, los inmigrantes aparecen relacionados de forma real o de forma imaginaria con todos los problemas sociales: el desempleo, la disolución cultural, el descenso del nivel educativo y la pérdida de calidad de los servicios sanitarios (Innerarity y Acha, 2010).

En resumen, a tenor de esta exploración teórica nos planteamos tres hipótesis: 
- Primera hipótesis (H1): La tasa de desempleo parece estar asociada a las actitudes restrictivas hacia la inmigración.

- Segunda hipótesis (H2): Aquellos países con mayor gasto en protección social y menores desigualdades sociales parece contribuir a generar actitudes más favorables hacia la inmigración.

- Tercera hipótesis (H3): La heterogeneidad étnica y racial no parece favorecer el compromiso igualitario.

Estas tres hipótesis las analizamos en los siguientes epígrafes.

\section{Analisis descriptivo de las actitudes}

En general la actitud de los ciudadanos europeos hacia la entrada de inmigrantes es restrictiva. La actitud restrictiva es una tendencia que va en aumento entre los años 2002 al 2010 en los 17 países estudiados. La ESE proporciona una variable sobre la actitud de la población europea ante la entrada de inmigrantes. Dicha variable aparece en las diferentes oleadas de la encuesta, que mediante una escala de 1 a 4 (“¿Permitiría usted la entrada de inmigrantes?", donde 1=mucho y 4=ningún inmigrante) nos muestra el aumento de las opiniones desfavorables: la media para el año 2002 fue de 2,24 y el año 2010 de 2,64 (véase tabla 1). Las opiniones restrictivas a 1 a entrada de inmigrantes han aumentado en determinados países, como Grecia, Hungría, República Checa, Portugal, Finlandia y Reino Unido.

Tabla 1: Opiniones y actitudes hacia la inmigración

\begin{tabular}{|c|c|c|c|c|c|c|c|}
\hline & \multicolumn{3}{|c|}{$\begin{array}{l}\text { ¿Cuándo deberían acceder los inmigan- } \\
\text { tes a los derechos y servicios públicos? }\end{array}$} & \multicolumn{2}{|c|}{$\begin{array}{l}\text { ¿La inmigración es mala } \\
\text { o buena para la econo- } \\
\text { mía? }\end{array}$} & \multicolumn{2}{|c|}{$\begin{array}{l}\text { ¿Los inmigrantes reciben } \\
\text { más o menos de lo que } \\
\text { ellos contribuyen? }\end{array}$} \\
\hline & $\mathrm{N}^{\mathrm{o}}$ & $\begin{array}{c}\text { Escala Media } \\
\text { (1=inmediatamente } \\
\text { y } 5=\text { =nunca })\end{array}$ & $\begin{array}{l}\text { Desv. } \\
\text { Tip. }\end{array}$ & $\begin{array}{c}\text { Escala } \\
\text { Media } \\
1=\text { mala y } \\
6=\text { buena }\end{array}$ & $\begin{array}{l}\text { Desv. } \\
\text { Tip. }\end{array}$ & $\begin{array}{c}\text { Escala } 0= \\
\text { Más y } \\
10=\text { Menos }\end{array}$ & $\begin{array}{l}\text { Desv. } \\
\text { Tip. }\end{array}$ \\
\hline \multicolumn{8}{|l|}{ Socialdemócrata } \\
\hline Suecia & 1729 & 2,78 & 1,115 & 2,45 & 0,625 & 4,57 & 1,759 \\
\hline Dinamarca & 1560 & 2,97 & 1,08 & 2,4 & 0,616 & 4,39 & 1,92 \\
\hline Finlandia & 2160 & 3,26 & 0,897 & 2,48 & 0,603 & 4,27 & 1,803 \\
\hline Noruega & 1521 & 3,02 & 1,057 & 2,54 & 0,589 & 4,38 & 1,918 \\
\hline Subtotal & 6970 & 3,02 & 1,046 & 2,47 & 0,61 & 4,39 & 1,849 \\
\hline \multicolumn{8}{|c|}{ Continental-Contributivo } \\
\hline Alemania & 2672 & 3,12 & 1,007 & 2,41 & 0,674 & 3,95 & 1,992 \\
\hline Francia & 2045 & 3 & 1,027 & 2,3 & 0,651 & 4,45 & 1,947 \\
\hline Bélgica & 1737 & 3,18 & 0,927 & 2,29 & 0,623 & 3,82 & 1,953 \\
\hline Holanda & 1748 & 3,26 & 0,946 & 2,46 & 0,593 & 4,2 & 1,674 \\
\hline Subtotal & 8202 & 3,1 & 0,987 & 2,37 & 0,645 & 4,1 & 1,923 \\
\hline \multicolumn{8}{|l|}{ Mediterráneo } \\
\hline España & 2485 & 3,03 & 0,986 & 2,39 & 0,636 & 4,32 & 2,217 \\
\hline Grecia & 1989 & 3,51 & 1,121 & 1,97 & 0,698 & 4,06 & 2,24 \\
\hline
\end{tabular}




\begin{tabular}{|c|c|c|c|c|c|c|c|}
\hline & \multicolumn{3}{|c|}{$\begin{array}{l}\text { ¿Cuándo deberían acceder los inmigan- } \\
\text { tes a los derechos y servicios públicos? }\end{array}$} & \multicolumn{2}{|c|}{$\begin{array}{l}\text { ¿La inmigración es mala } \\
\text { o buena para la econo- } \\
\text { mía? }\end{array}$} & \multicolumn{2}{|c|}{$\begin{array}{l}\text { ¿Los inmigrantes reciben } \\
\text { más o menos de lo que } \\
\text { ellos contribuyen? }\end{array}$} \\
\hline & $\mathrm{N}^{\mathrm{o}}$ & $\begin{array}{c}\text { Escala Media } \\
\text { (1=inmediatamente } \\
\text { y } 5=\text { nunca) }\end{array}$ & $\begin{array}{l}\text { Desv. } \\
\text { Tip. }\end{array}$ & $\begin{array}{c}\text { Escala } \\
\text { Media } \\
1=\text { mala y } \\
6=\text { buena }\end{array}$ & $\begin{array}{l}\text { Desv. } \\
\text { Tip. }\end{array}$ & $\begin{array}{c}\text { Escala } 0= \\
\text { Más y } \\
10=\text { Menos }\end{array}$ & $\begin{array}{l}\text { Desv. } \\
\text { Tip. }\end{array}$ \\
\hline Portugal & 2018 & 2,9 & 0,869 & 2,35 & 0,601 & 4,65 & 2,038 \\
\hline Subtotal & 6942 & 3,1 & 0,897 & 2,24 & 0,671 & 4,34 & 2,185 \\
\hline \multicolumn{8}{|l|}{ Liberal } \\
\hline Reino Unido & 2315 & 3,32 & 0,922 & 2,26 & 0,685 & 3,9 & 2,355 \\
\hline \multicolumn{8}{|l|}{ Este Europa } \\
\hline Chequia & 1916 & 3,6 & 0,903 & 2,15 & 0,654 & 3,78 & 1,965 \\
\hline Polonia & 1490 & 3,32 & 0,864 & 2,46 & 0,649 & 4,49 & 1,888 \\
\hline Subtotal & 3406 & 3,48 & 0,897 & 2,29 & 0,669 & 4,09 & 0,689 \\
\hline \multicolumn{8}{|c|}{ Otros Este Europa } \\
\hline Rumanía & 1695 & 3,46 & 0,956 & 2,42 & 0,767 & 5,04 & 2,126 \\
\hline Lituania & 1852 & 3,61 & 0,95 & 2,12 & 0,739 & 4,27 & 2,27 \\
\hline Subtotal & 3547 & 3,54 & 0,956 & 2,27 & 0,768 & 4,63 & 2,237 \\
\hline Total & 50905 & 3,26 & 1,028 & 2,3 & 0,679 & 4,4 & 2,047 \\
\hline
\end{tabular}

Fuente: Elaboración propia con datos de la ESS (2008-09).

Los ciudadanos europeos prefieren la admisión de inmigrantes de la misma raza que la de aquellos procedentes de países pobres de fuera de Europa (H3). Un 19\% de los encuestados señalan que no debe entrar ningún inmigrante de países pobres de fuera de Europa, pero cuando se trata de inmigrantes de la misma raza el rechazo es ostensiblemente menor: 9,7\% (ESE, 2010).

$\mathrm{La}$ actitud restrictiva respecto a la entrada de inmigrantes guarda cierta similitud con la tendencia de la opinión restrictiva respecto al "compromiso igualitario," que figura solamente en la ESE del año 2008. Dicho "compromiso igualitario" (“¿Cuándo deberían acceder los inmigrantes a los derechos y servicios sociales?”, medido en una escala de 1 a 5 , donde $1=$ inmediatamente y $5=$ nunca), presenta una media inclinada hacia opiniones restrictivas $(3,26)$ en el año 2008 (véase tabla 1). Por encima de dicha media aparecen casi los mismos países: Grecia, República Checa, Reino Unido, Finlandia y Países Bajos. La posición mayoritaria es restrictiva e indica que el acceso de los inmigrantes a los derechos sociales se debe conceder "una vez que los inmigrantes hayan obtenido la ciudadanía"; en segundo lugar le sigue la posición intermedia, que vincula el acceso de los derechos a "haber trabajado y pagado los impuestos al menos un año". La tendencia general es restrictiva, por el contrario, lógicamente los inmigrantes reclaman el acceso a 1 os derechos en mayor proporción que los nativos. La opinión sobre el acceso a los derechos sociales es aún mucho más desfavorable cuando se trata de inmigrantes de países pobres de fuera de Europa (H3). 
Gráfico 1. ¿Cuándo deberían los inmigrantes acceder a los derechos y servicios sociales?

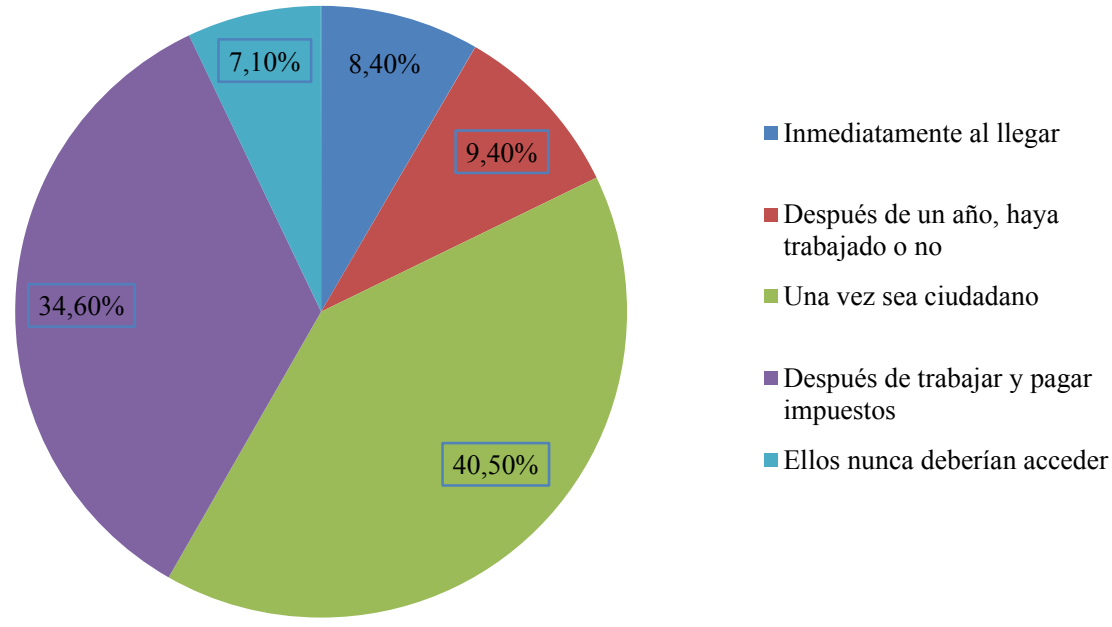

Fuente: Elaboración propia, datos ESE 2008.

Por otra parte, el examen de las categorías extremas nos ofrece mayor claridad en el análisis. Dichas categorías extremas sobre el acceso de los inmigrantes a los derechos sociales son, como hemos visto atrás, reconocer los derechos "inmediatamente al llegar" y "nunca" deberían ser reconocidos los derechos. Las opiniones extremadamente restrictivas de los individuos quedan más claramente marcada a partir de la idea de que los inmigrantes nunca deberían acceder a los derechos sociales, para lo cual hemos realizado un análisis de regresión logística tomando como referencia la categoría intermedia (acceso a los derechos después de trabajar y pagar los impuestos, ver tabla 1 anexa). En este sentido las categorías de mayor peso explicativo son (H1): los bajos niveles de estudios, los ingresos económicos bajos, la edad (particularmente los mayores de 55 años), el tipo de contrato laboral, el desempleo y el posicionamiento político. El género no es si gnificativo en las opiniones. En conjunto pesan más en las opiniones extremas las características de los individuos y las socio-económicas que las variables contextuales y políticas.

\section{Modelos de bienestar y compromiso igualitario}

En la tabla 2 aparecen los países agrupados por modelos teóricos de bienestar a meros efectos de plantear la hipótesis (H2) sobre la posible relación entre la generosidad de los Estados del Bienestar y la mitigación de la competencia en el mercado de trabajo y su posible efecto sobre las actitudes (Morissen, 2008; Menz, 2008). En la literatura especializada hay un cierto consenso en la identificación de los países que conforman el modelo escandinavo y el modelo liberal británico (EspingAndersen, 2000; Menz, 2005), pero la agrupación de los otros modelos de bienestar 
es discutible, especialmente el llamado modelo de bienestar mediterráneo (Ferrara, 2005; Moreno, 2010). De hecho, la agrupación de modelos de bienestar se podría entender como una agrupación por proximidad territorial entre los países.

La agrupación de países de acuerdo a modelos de bienestar parece contribuir a una cierta explicación de las asociaciones entre variables contextuales socioeconómicas y actitudes, como son las pensiones por desempleo de larga duración, el riesgo de pobreza, el nivel de riqueza (PIB), el gasto en protección social y el nivel de desigualdad (Índice Gini). Es decir, la actitud hacia los inmigrantes correlaciona con variables ligadas a la riqueza y a su redistribución (H2). Sin embargo, estas correlaciones varían según el modelo de bienestar y los países. 
Tabla 2:

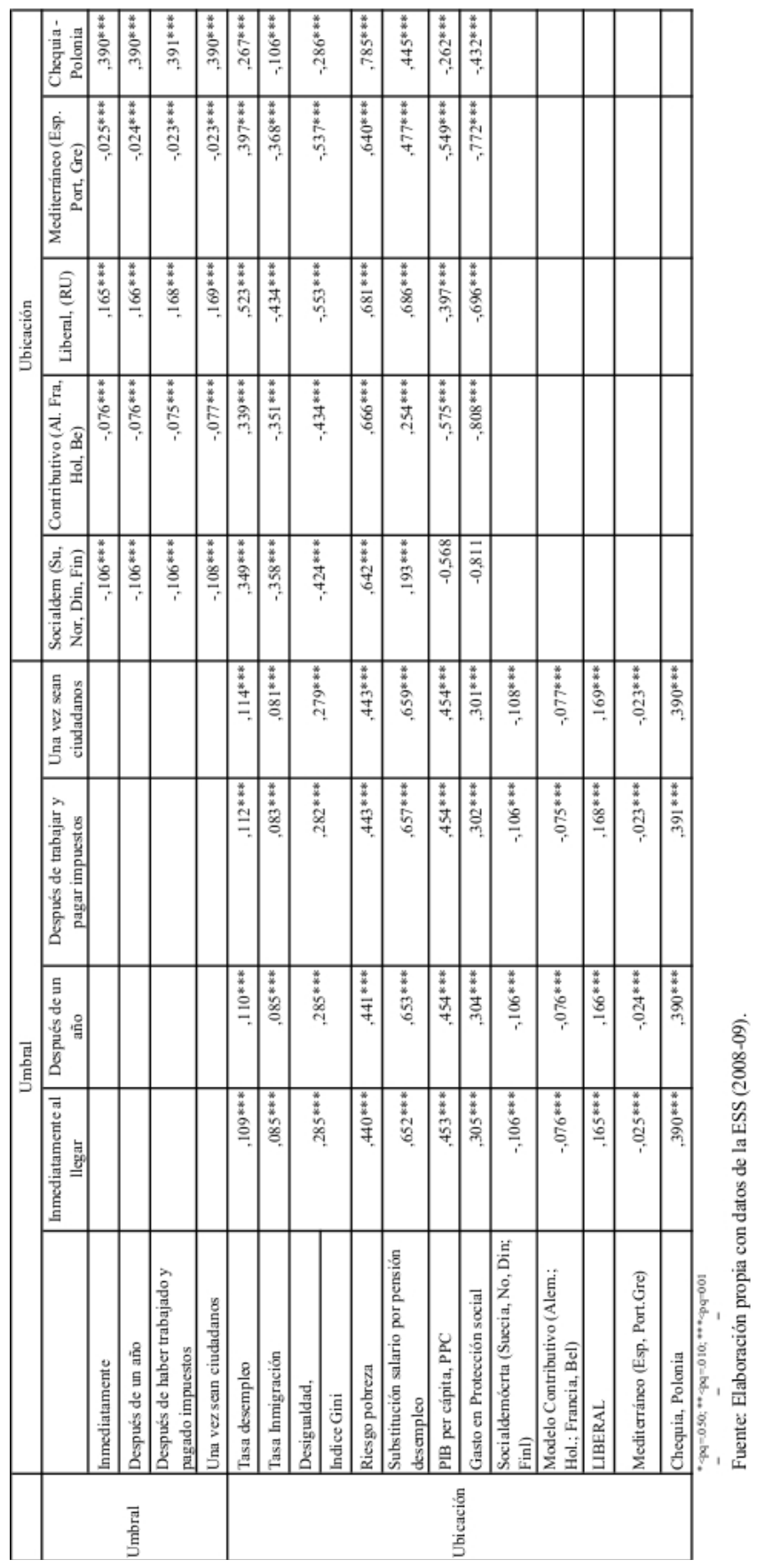




\subsection{Modelo Escandinavo}

En primer lugar, el modelo de bienestar escandinavo es universalista (véase Sarasa, 1995; Menz, 2005; Ferrara, 2005; Magnusson, et al. 2008; entre otros), caracterizado por un bajo riesgo de pobreza, una protección social generosa, con alta protección social, altas prestaciones por desempleo, alto gasto en exclusión social y alto PIB per cápita en comparación con otros países (véase tabla 3 y tabla anexa 2). Este modelo cuenta con un sistema de concertación social neo-corporatista y una importante participación institucional de los sindicatos (participan en la gestión del sistema de pensiones y el seguro de desempleo). Estos países cuentan con la tasa de afiliación más alta de Europa, incluso para los inmigrantes. Aunque hay diferencias entre los países escandinavos, p. e., la tasa de afiliación sindical en Suecia es del 55\% para los nativos y del $42 \%$ para los inmigrantes; en Dinamarca es del $61 \%$ y $55 \%$ respectivamente, en Noruega del $49 \%$ y $35 \%$ y en Finlandia del 59\% y 55\% respectivamente. Queremos subrayar aquí que la afiliación de los inmigrantes es precisamente un factor importante para la integración de éstos, para su aceptabilidad social y su socialización en la diversidad.

Los países escandinavos hoy constituyen el paradigma del "compromiso igualitario." En la tabla 3 se muestra como Suecia registra la actitud muy favorable al acceso de los inmigrantes a los derechos sociales, Dinamarca ligeramente favorable y Noruega se sitúa en la media. Mientras que en relación a la admisión de nuevos inmigrantes sólo es favorable Suecia. Finlandia registra actitudes desfavorables y restrictivas. La tasa de inmigración solo es alta en Suecia: este es un país de antigua inmigración ligada en buena parte al asilo político.

En los países escandinavos las variables que se asocian con las actitudes favorables hacia la inmigración son la protección social, el escaso riesgo de pobreza y el nivel de riqueza (PIB), que correlacionan de manera fuerte y significativa con el reconocimiento de los derechos sociales a los inmigrantes (H2). También correlaciona, aunque de forma moderada, con la desigualdad y el desempleo y de forma débil con la sustitución salarial de la pensión por desempleo. Posiblemente el generoso Estado del Bienestar escandinavo contribuye a amortiguar las tensiones sociales derivadas de la competencia por los recursos de bienestar y de empleo. Además, en estos países la opinión pública considera que los inmigrantes reciben más de lo que aportan, lo que probablemente esté asociado a que estos países han tenido una importante tradición de asilo político.

En este grupo de países destaca Suecia, el mejor ejemplo del modelo social demócrata: cuenta con una importante política de integración social para incorporar a la inmigración, integrarla en los sindicatos y con acceso a los servicios y derechos sociales. Este país tiene el mejor indicador (83 puntos) en el índice comparado de políticas de integración social del Índice Mipex (2010). 
Tabla 3: Variable dependiente: ¿cuándo deberían los inmigrantes obtener los derechos sociales y acceder a los servicios públicos?

\begin{tabular}{|c|c|c|c|c|c|c|c|c|c|c|c|c|c|c|c|c|c|}
\hline & & 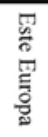 & & & & & & & 垔. & & & 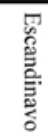 & $\begin{array}{l}\frac{3}{0} \\
\frac{0}{0} \\
\frac{0}{0}\end{array}$ & & & 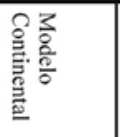 & \\
\hline 交 & 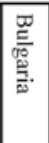 & 全 & 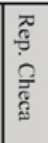 & . & $\begin{array}{l}\text { है. } \\
\text { है. }\end{array}$ & 总 & 要 & 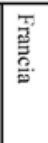 & 클 & 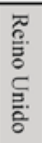 & 巽 & 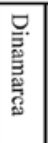 & 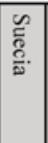 & 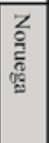 & 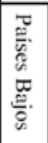 & 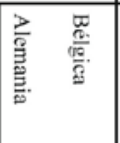 & \\
\hline 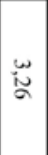 & 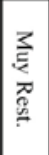 & 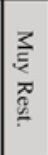 & 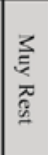 & 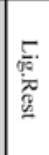 & 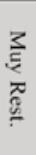 & $\frac{z}{\pi}$ & $\frac{3}{0}$ & $\begin{array}{l}3 \\
\frac{3}{0} \\
\text { 을 }\end{array}$ & $\Xi$ & 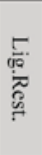 & 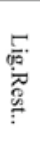 & 䆑. & 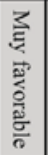 & $\frac{3}{0 .}$ & 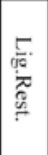 & 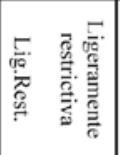 & 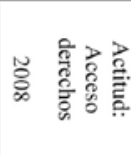 \\
\hline 莕 & $\begin{array}{l}\overrightarrow{\widetilde{R}} \\
\stackrel{0}{*}\end{array}$ & 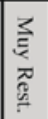 & 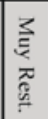 & 竞 & 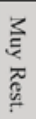 & $\underset{\tilde{Q}}{\tilde{Q}}$ & $\underset{\widetilde{Q}}{\tilde{R}}$ & $\underset{\mathscr{O}}{\widetilde{R}}$ & 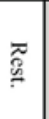 & $\underset{\widetilde{\widetilde{R}}}{\widetilde{R}}$ & 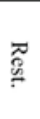 & $\begin{array}{l}\overrightarrow{\widetilde{0}} \\
\stackrel{0}{\mathscr{m}}\end{array}$ & 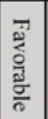 & 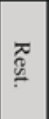 & $\underset{\tilde{\pi}}{\mathscr{q}}$ & $\underset{\mathscr{O}}{\widetilde{R}}$ & 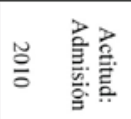 \\
\hline$\stackrel{t}{u}$ & 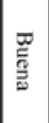 & $\frac{3}{12}$ & 胥 & 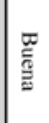 & z & $\frac{3}{w}$ & $\frac{3}{w}$ & $\frac{3}{w}$ & $\frac{3}{w 2}$ & $\frac{3}{w}$ & 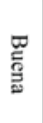 & 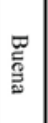 & 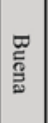 & 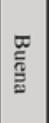 & 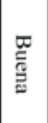 & 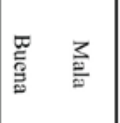 & 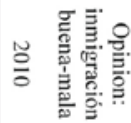 \\
\hline 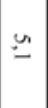 & 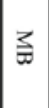 & $\frac{3}{5}$ & $\varpi$ & $\varpi$ & $>$ & $>$ & 3 & 3 & $\varpi$ & $>$ & $\varpi$ & 3 & $\frac{3}{5}$ & $\varpi$ & $>$ & 3 & 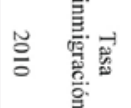 \\
\hline$\because 0$ & $>$ & $>$ & $\varpi$ & 3 & 3 & $>$ & $\frac{3}{5}$ & 3 & 3 & 3 & 3 & 3 & 3 & $\frac{3}{w}$ & $\varpi$ & 3 & 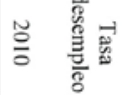 \\
\hline $\bar{u}$ & 3 & ミ & క & $>$ & $>$ & $\xi$ & $\frac{3}{5}$ & $\varpi$ & $>$ & 3 & $\varpi$ & 飞 & 늘 & క & 3 & 3 & 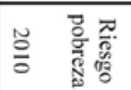 \\
\hline $\begin{array}{c}\vec{f} \\
\substack{\infty \\
\infty}\end{array}$ & る & 3 & 3 & $\frac{3}{m}$ & 3 & 3 & 3 & $\frac{3}{5}$ & & 3 & 3 & 3 & $>$ & 3 & 3 & 3 & 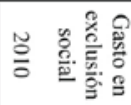 \\
\hline$\stackrel{N}{\alpha}$ & z & $\underline{z}$ & $\frac{3}{w}$ & $\frac{z}{\omega}$ & 3 & $\varpi$ & $\varpi$ & 3 & 3 & $>$ & 3 & $\frac{3}{5}$ & $\frac{3}{5}$ & 3 & 3 & 3 & 冾 \\
\hline$\underset{\substack{\infty \\
\sim}}{\stackrel{\infty}{\sim}}$ & $\frac{3}{\varpi}$ & 引 & $\varpi$ & $\varpi$ & 3 & 3 & $\varpi$ & 3 & $\xi$ & $>$ & 3 & $\xi$ & 3 & $\xi$ & 3 & $\xi$ & 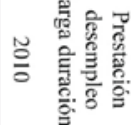 \\
\hline$\overline{\mathrm{c}}$ & 3 & 3 & 3 & 굴 & 3 & 3 & 3 & $>$ & $>$ & $>$ & $>$ & $\xi$ & $\frac{3}{3}$ & $\xi$ & 3 & 33 & 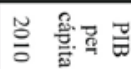 \\
\hline$\ddot{b}$ & 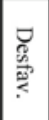 & 总 & 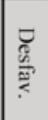 & & 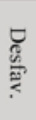 & 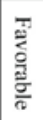 & $\frac{5}{5 \cdot}$ & 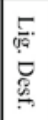 & 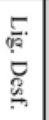 & 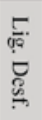 & 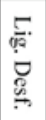 & 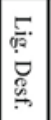 & 孞 & 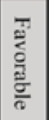 & 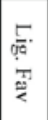 & 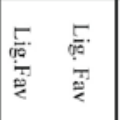 & 음 \\
\hline
\end{tabular}




\subsection{Modelo continental}

En segundo lugar, el modelo continental, bismarkiano y neocorporatista (Alemania, Holanda y Bélgica) cuenta con un sistema de bienestar de carácter contributivo basado en la ocupación (Ferrara, 2005:59-65). Las tasas de afiliación sindical sólo es importante en Bélgica (41\% para los nativos y $40 \%$ para los inmigrantes), en los otros países son mucho más bajas: Alemania (14\% y $6 \%$ respectivamente) y Países Bajos (21\% y $16 \%$ respectivamente) y los inmigrantes apenas tienen presencia en los sindicatos. Además, en estos países, los sindicatos tienen divisiones ideológicas internas entre corrientes, lo que refleja la herencia de la lucha por el control de las instituciones entre iglesia y estado en el proceso de modernización (Sarasa, 1995:165; Menz, 2005:44-47).

La actitud hacia el acceso de los inmigrantes a los derechos sociales es ligeramente restrictiva, lo que diferencia a estos países de los escandinavos. Asimismo, la actitud hacia la entrada de inmigrantes es restrictiva. Estos tres países tienen inmigración antigua y su tasa es hoy alta. La tasa de desempleo es baja, así como el riesgo de pobreza. El nivel de gasto en protección social y en prestaciones por desempleo en Alemania, Países Bajos y Bélgica es al to y muy alto en términos comparativos (tabla 3 ).

Las variables más estrechamente asociadas con las actitudes restrictivas son: el riesgo de pobreza, la tasa de desempleo (H1) y las pensiones por desempleo de larga duración, lo que se puede interpretar desde la teoría de la competencia por los recursos de empleo y de protección social. Por el contrario, las variables que parecen asociarse con actitudes equitativas al compromiso igualitarista son: un índice bajo de desigualdad, el gasto en protección social y el nivel de riqueza medido por el PIB. Nótese que en todos los modelos de bienestar el nivel de riqueza per cápita (PIB) tiene una correlación fuerte y significativa con la actitud hacia la inmigración, como también ha puesto de relieve Mayda (2006).

En este modelo el caso más significativo es el de Alemania, donde la política ha tenido históricamente $(1950,1960,1970)$ una concepción de la inmigración por un tiempo determinado (Gastarbaitersystem), lo que ha comportado dificultades para acceder a la nacionalidad. La política de inmigración tiene una importante componente étnico-nacional (Schierup, et. al. 2006:109). Pero en los últimos años la inmigración indocumentada ha aumentado en Alemania y está siendo utilizada para flexibilizar el mercado de trabajo a través de nuevas formas de contratación y trabajos informales con bajos salarios. Este hecho es precisamente una fuente de tensión entre la incertidumbre del trabajo informal y el empleo regular contributivo para el sistema de bienestar. La tensión entre la inmigración y el bienestar está relacionada con la baja contribución de los inmigrantes al sistema de protección social, porque éstos tienen bajos salarios, empleos precarios, temporales, periodos de desempleo, o incluso trabajan en la economía informal. 


\subsection{Modelo Liberal}

En tercer lugar, el Reino Unido representa el modelo liberal más genuino. En este país el sistema de bienestar es universal, pero de mínimos complementado con sistemas privados de pensiones. El sistema de relaciones laborales se caracteriza por el "voluntarismo" en el reconocimiento de las partes, lo que implica escasas garantías jurídicas y un sistema de negociación colectiva muy descentralizado. La tasa de afiliación tiende a reducirse desde hace décadas. Hoy esta es del 17\% para los nativos y apenas un 7\% para los inmigrantes. La tasa de inmigración está ligeramente por encima de la media, pero es un país con una larga historia de inmigración y una fuerte "racialización" del mercado laboral (Castles, 2006; Schierup, et. al. 2006).

La tendencia general de las actitudes es restrictiva tanto para la admisión como para el acceso de los inmigrantes a los derechos sociales. Incluso la opinión pública cree (en mayor proporción que en otros países) que la inmigración es mala para la economía y que los inmigrantes reciben más de lo que aportan a la sociedad (tabla 1). Las actitudes negativas correlacionan de manera sustancial y significativa con las pensiones por desempleo y la tasa de desempleo, lo que constituye una diferencia con los otros modelos de bienestar. A lo que hay que añadir la correlación sustancial con el riesgo de pobreza (H1). Por el contrario, las actitudes sobre el acceso de los inmigrantes al bienestar correlacionan de forma negativa, pero también fuerte y significativamente con el gasto en protección social (aunque en menor medida que los modelos escandinavo y continental, H2). Igualmente también correlaciona de manera negativa las desigualdades sociales (Índice de Gini).

El suma, el modelo británico representa una orientación neoliberal y postfordista de la política inmigratoria. Ésta es funcional con la flexibilización del mercado laboral. Pero al mismo tiempo el Reino Unido tiene la política antidiscriminatoria más elaborada de Europa, lo que se refleja en su legislación laboral (H3) y el en índice Mipex, que veremos más adelante. La política y la legislación antidiscriminatoria se deben a la existencia de una antigua inmigración y a los descendientes de la misma (hoy ciudadanos británicos), así como al asentamiento consolidado de minorías étnicas (Schierup, et. al. 2006).

\subsection{Modelo Mediterráneo}

En cuarto lugar, los países agrupados en el modelo mediterráneo presentan un cuadro diverso. Francia cuenta con un sistema de bienestar contributivo, con altas prestaciones por desempleo y protección social, así como un alto PIB per capita. Además es un país con inmigración antigua y una importante diversidad étnica y racial. Por el contrario, España, Portugal y Grecia, son países de nueva inmigración, altas tasas de desempleo, alto riesgo de pobreza y bajas prestaciones por desempleo, así como bajo gasto social. Estos países cuentan con un sistema de bienestar contri- 
butivo, pero complementado con el apoyo de la solidaridad familiar y sistemas de seguros y pensiones privados (Moreno, 2010).

El sistema de relaciones laborales se caracteriza por una importante informalidad y muy bajas tasas de afiliación sindical. En Francia la afiliación sindical apenas llega al 7\% para los nativos y al 12\% para los inmigrantes. En España es el 13\% y 3\% respectivamente. En Portugal el 7\% y 6\% y en Grecia el 6\% y 2\% respectivamente. La baja afiliación de los inmigrantes quizás se deba a que estos países (excepto Francia) son de reciente inmigración. No obstante, la baja afiliación de la inmigración es un hándicap para la política de integración, lo que además debilita la capacidad de acción colectiva de los sindicatos (H3).

En Francia, España y Portugal las actitudes sobre el reconocimiento de los derechos de los inmigrantes para acceder a los servicios sociales se sitúan en la media de los 17 países estudiados, lo que podemos entender como equitativa en la medida que vincula deberes y derechos ("acceder después de trabajar y pagar impuestos"). Pero en relación a la admisión de inmigrantes la actitud dominante es restrictiva. El caso de Grecia merece una consideración aparte porque la actitud es muy restrictiva tanto para el acceso a los derechos sociales como para la admisión en el país. En estos cuatro países la opinión es mala sobre la contribución de los inmigrantes a la economía.

Las variables con las cuales hay una asociación sustancial y significativa de las actitudes son el riesgo de pobreza (H1), las prestaciones por desempleo de larga duración y el desempleo. Por el contrario, contribuyen a conformar actitudes más positivas el gasto en protección social y el índice de desigualdad (H2). El índice de desigualdad y la tasa de desempleo actúan de manera más semejante al modelo liberal británico que a los otros modelos.

En España, Grecia y Portugal una parte importante de la inmigración trabaja en la pequeña empresa, con contratos temporales, como falsos autónomos, en la economía informal o está en situación irregular, lo que genera que muchos inmigrantes estén en el "limbo" porque no pueden acceder con plenitud a los derechos sociales. Según Schierup, et. al. (2006:250), el estado del bienestar conservador-corporatista y el mediterráneo son relativamente tolerantes con la exclusión social de los no nacionales y con las minorías étnicas en comparación con los países nórdicos (H3).

\section{Políticas de protección social e integración de la inmigración}

En los modelos de bienestar examinados se observan diferencias internas entre los países que los componen, lo que se manifiesta especialmente en el modelo escandinavo: Finlandia y Dinamarca registran una fuerte diferencia respecto a $\mathrm{S}$ uecia y Noruega; lo mismo ocurre en el modelo mediterráneo: Francia y Grecia registran también fuertes diferencias. Por ello es más apropiados establecer ciertas correlaciones entre políticas de bienestar y actitudes. En efecto, las políticas de bienestar están relacionadas con las actitudes hacia la inmigración. Esto se observa particularmente en el caso de las actitudes extremas de quienes reclaman que no entre 
"ningún inmigrante" (ESE, 2010). Esta opinión extremadamente restrictiva tiene una correlación fuerte negativa con las prestaciones por desempleo a largo plazo ( $\mathrm{r}$-, $\left.598^{* *}\right)$, con el gasto en protección social $\left(\mathrm{r}-, 538^{* *}\right)$ y con el PIB per cápita ( $\mathrm{r}$, 494*). Asimismo, algunas opiniones, como que "los inmigrantes hacen peor al país para vivir" (ESE 2010) correlacionan de forma sustancial y positiva con el riesgo de pobreza $\left(, 499^{* *}\right)$, lo que nos sugiere indirectamente que la reducción de la pobreza contribuye a la modificación de las opiniones. En este sentido el riesgo de pobreza correlaciona de manera sustancial y negativa con el gasto por exclusión por habitante $\left(-, 534^{* *}\right)$ y con la prestación por desempleo a largo plazo $(-, 592 * * *)$, y de forma fuerte y positiva con el desempleo $\left(, 747^{* * *}\right)$. En suma (H2), todo ello significa que las políticas de protección social, las prestaciones y subsidios de desempleo, así como la lucha contra el desempleo y el nivel de riqueza por habitante pueden contribuir a la formación de actitudes y opiniones menos hostiles hacia la inmigración.

\subsection{Políticas de integración y actitudes: Índice Mipex}

El Índice MIPEX consiste en un indicador sintético construido mediante siete variables: 1) acceso de los inmigrantes al mercado de trabajo, que mide la inclusión y exclusión de los inmigrantes de determinados puestos de trabajo; el ajuste del flujo de inmigrantes a la oferta de empleo, las facilidades para la obtención del permiso de trabajo y el acceso a los derechos sociales; 2) la reunificación familiar, que mide las facilidades y requisitos; 3 ) las facilidades para la obtención del permiso de residencia a largo plazo, que mide particularmente el tiempo mínimo requerido para la concesión del mismo; 4) la participación política, que mide que derecho de asociación política y sindical, así como la participación como representante y votante; 5) el acceso a la nacionalidad, variable relativa a las exigencias de estancia temporal y requisitos para obtener la ciudadanía; 6) medidas antidiscriminatorias, que mide la discriminación por motivos étnicos, raciales y religiosos y las posibilidades de reclamar medidas de protección contra la discriminación.

El análisis de correspondencias múltiples nos permite clasificar y ordenar los países según las políticas de integración (Mipex, 2010) y las actitudes hacia la inmigración a partir de dos ejes:

1. Integración desfavorable versus favorable: El primer eje horizontal ofrece una clasificación entre dos polos (gráfico 1): admisión de ningún inmigrante/políticas de integración desfavorables y admisión de muchos inmigrantes/políticas de integración favorables. Por un lado, aquellos países como Grecia, República Checa y Hungría, presentan actitudes inclinadas a no admitir ningún inmigrante, lo que concuerda con el índice sintético Mipex. Ello nos indica la existencia de políticas de integración por debajo de la media, lo que podríamos considerar como desfavorables. Precisamente en estos países el peso de la extrema derecha nacionalista está por encima de la media (en 
Hungría es del 10,6\%; en la República Checa el 4,9\%; en Grecia del 3,5\%, la media es del 2,7\%, ESE, 2010).

Gráfico 2: Actitud hacia la inmigración y políticas de integración

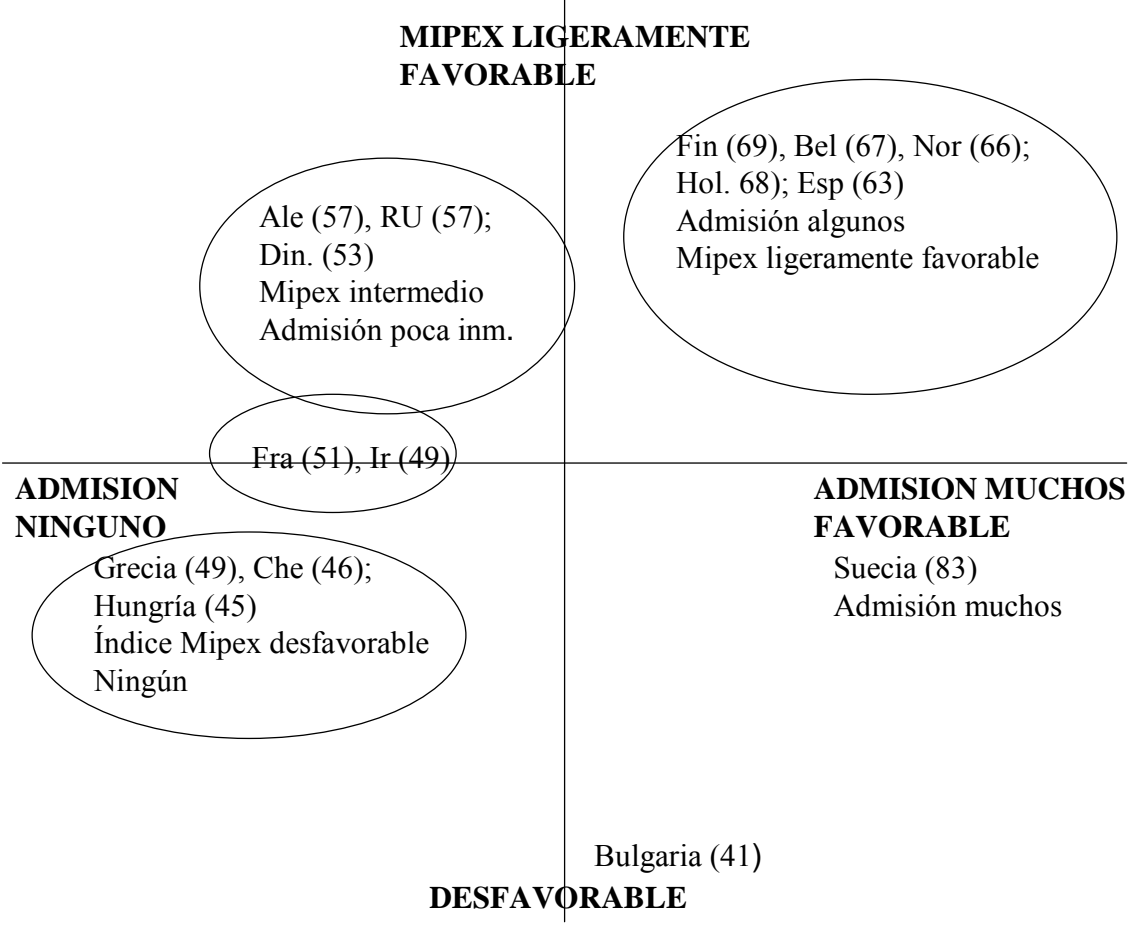

Fuente: Elaboración propia con datos ESE (2010) y Índice Mipex (2010) Entre paréntesis figuran los puntos Mipex. Media 52 puntos.

Por otro lado, en el extremo opuesto, se halla Suecia, donde los ciudadanos tienen una actitud más tolerante, abierta. La política de integración tiene el índice Mipex favorable más favorable. Este país se ha caracterizado por impulsar políticas de igualdad de oportunidades y no discriminación por razones de género, raza y etnia. Entre los años 2008 y 2010 ha impulsado la llamada Estrategia de Integración que ha permitido mejorar los indicadores de las siete áreas evaluadas por el índice Mipex (véase tabla 4). La mejor puntuación la ha obtenido en materia de movilidad laboral, con especial reconocimiento oficial de las cualificaciones profesionales obtenidas en otros países. El permiso de residencia es de un año y no hay distinción entre ciudadanos y no ciudadanos de la UE para acceder al mercado de trabajo. Los inmigrantes son informados de sus derechos laborales, sindicales, de participación y reunificación familiar. Los programas de integración ofrecen cursos de formación en la lengua sueca que imparte el Servicio Público de Empleo. Éste cuenta 
con una activa influencia institucional de los sindicatos (Magnusson, et. al. 2008)). El flujo de inmigración está estrictamente regulado, pero también garantiza la integración con medidas de igualdad, obligaciones y seguridad.

2. Integración ligeramente favorable versus desfavorable: Es el segundo y se define mediante el eje vertical de políticas de integración ligeramente favorables versus políticas de integración desfavorables. En torno a este eje se agrupan en el extremo superior dos grupos de países: a) aquellos países que han tenido históricamente mucha inmigración, como el Reino Unido y Alemania, además de Dinamarca. Los ciudadanos de estos países se inclinan a la admisión de poca inmigración y su índice Mipex es intermedio o incluso está por debajo de la media en Francia e Irlanda; b) el otro grupo lo forman Finlandia, Bélgica, Países Bajos y España, donde los ciudadanos están dispuestos a admitir algunos inmigrantes y las políticas de integración aparecen clasificadas en el índice Mipex como ligeramente favorables. Y en el extremo inferior figura Bulgaria, con muy baja puntuación en el índice Mipex y sin apenas inmigración.

En suma, en la tabla 4 se desglosa cada una de las áreas evaluadas por el Índice Mipex (2010). Las medias más bajas se obtienen en el acceso a la educación y a la nacionalidad y a la participación política, a los derechos sociales y de ciudadanía. Y, en cambio, la movilidad laboral obtiene una de las puntuaciones más altas, lo que califican algunos analistas como "inmigración laborizada" (Schierup, et. al 2006). Pero sin duda, uno de los avances legales más importantes en los últimos años se ha logrado en materia de anti-discriminación por razón de género, raza y etnia gracias a las Directivas Europeas, lo que se ha debido a una reacción de la Comisión Europea ante el pujante avance de la extrema derecha en algunos países europeos.

Tabla 4: Indicadores políticas de integración

\begin{tabular}{|l|l|c|c|c|c|c|c|c|}
\hline & & $\begin{array}{c}\text { Movili- } \\
\text { dad }\end{array}$ & $\begin{array}{c}\text { Reagrupación } \\
\text { Familiar }\end{array}$ & $\begin{array}{c}\text { Educa- } \\
\text { ción }\end{array}$ & $\begin{array}{c}\text { Partici- } \\
\text { pación } \\
\text { política }\end{array}$ & $\begin{array}{c}\text { Residencia } \\
\text { Larga } \\
\text { Duración }\end{array}$ & $\begin{array}{c}\text { Acceso } \\
\text { Nacio- } \\
\text { nalidad }\end{array}$ & $\begin{array}{c}\text { Anti- } \\
\text { Discrimi- } \\
\text { nación }\end{array}$ \\
\hline \multirow{2}{*}{$\begin{array}{l}\text { Modelo } \\
\text { Conti- } \\
\text { nental }\end{array}$} & Bélgica & 53 & 68 & 66 & 59 & 79 & 69 & 79 \\
\cline { 2 - 10 } & Alemania & 77 & 60 & 43 & 64 & 50 & 59 & 48 \\
\cline { 2 - 10 } & Países Bajos & 85 & 64 & 51 & 79 & 68 & 65 & 68 \\
\hline \multirow{2}{*}{$\begin{array}{l}\text { Modelo } \\
\text { Escandi- } \\
\text { navo }\end{array}$} & Suecia & 100 & 84 & 77 & 75 & 78 & 79 & 88 \\
\cline { 2 - 10 } & Noruega & 73 & 68 & 63 & 94 & 61 & 41 & 59 \\
\cline { 2 - 10 } & Dina-marca & 73 & 37 & 61 & 62 & 66 & 33 & 47 \\
\hline \multirow{2}{*}{$\begin{array}{l}\text { Modelo } \\
\text { Británico }\end{array}$} & Finlandia & 71 & 70 & 63 & 87 & 58 & 57 & 48 \\
\cline { 2 - 10 } & Reino Unido & 55 & 54 & 58 & 53 & 31 & 59 & 88 \\
\hline
\end{tabular}




\begin{tabular}{|l|l|c|c|c|c|c|c|c|}
\hline & & $\begin{array}{c}\text { Movili- } \\
\text { dad }\end{array}$ & $\begin{array}{c}\text { Reagrupación } \\
\text { Familiar }\end{array}$ & $\begin{array}{c}\text { Educa- } \\
\text { ción }\end{array}$ & $\begin{array}{c}\text { Partici- } \\
\text { pación } \\
\text { política }\end{array}$ & $\begin{array}{c}\text { Residencia } \\
\text { Larga } \\
\text { Duración }\end{array}$ & $\begin{array}{c}\text { Acceso } \\
\text { Nacio- } \\
\text { nalidad }\end{array}$ & $\begin{array}{c}\text { Anti- } \\
\text { Discrimi- } \\
\text { nación }\end{array}$ \\
\hline \multirow{4}{*}{$\begin{array}{l}\text { Mediterrá- } \\
\text { neo }\end{array}$} & Francia & 49 & 52 & 29 & 44 & 46 & 59 & 77 \\
\cline { 2 - 10 } & Espana & 84 & 85 & 48 & 56 & 78 & 39 & 49 \\
\cline { 2 - 10 }$y$ & Grecia & 50 & 49 & 42 & 40 & 56 & 57 & 50 \\
\cline { 2 - 10 }$y$ & Portugal & 94 & 91 & 63 & 79 & 69 & 82 & 84 \\
\hline \multirow{3}{*}{ Este } & Polonia & 48 & 67 & 29 & 13 & 65 & 35 & 36 \\
\cline { 2 - 10 } & Rep. Checa & 55 & 66 & 44 & 13 & 65 & 33 & 44 \\
\cline { 2 - 10 } & Hungría & 41 & 61 & 12 & 33 & 60 & 31 & 75 \\
\cline { 2 - 10 } & Bulgaria & 40 & 51 & 15 & 17 & 57 & 24 & 80 \\
\hline
\end{tabular}

Fuente: Índice Mipex (2010):

Las cuatro directivas impulsadas a partir del Tratado de Ámsterdam (1997) y de la Cumbre de Tempere (1999) han jugado un efecto inducido en la transposición al derecho nacional de los estados miembros y la mejora de la legislación relativa a la no-discriminación (EU, 2011). Además, la UE ha recomendado el impulso de un código deontológico para los medios de comunicación -que tienen una enorme influencia sobre la opinión pública- con la finalidad de propiciar un tratamiento ecuánime sobre la inmigración (Agencia de los Derechos Fundamentales, 2011). Sin embargo, la aplicación y desarrollo de la normativa en los convenios colectivos es menos optimista, habida cuenta de su todavía débil impulso en determinados países, entre ellos España, Grecia, Republica Checa, Polonia, lo que contrasta con países pioneros en esta materia como son el Reino Unido y Bélgica (Pajares, Jubany, 2011:197-200).

\section{Conclusiones}

En primer lugar (H1), las variables contextuales como la tasa de desempleo y el riesgo de pobreza están asociados a las actitudes restrictivas y desfavorables hacia la inmigración, lo que nos indica que la competencia por los recursos de empleo y bienestar están en la base de las actitudes hostiles hacia la inmigración. Asimismo, la tasa de inmigración también está asociada a las mencionadas actitudes negativas, pero la influencia de ésta es menos evidente porque la tasa de inmigración actúa particularmente cuando la inmigración se concentra en un territorio determinado. Las variables individuales y socio-económicas también confirman la influencia de la competencia por los escasos recursos de empleo y bienestar como explicación de las actitudes restrictivas y desfavorables. El perfil individual de quienes tienen actitudes hostiles lo constituyen los desempleados, quienes tienen contratos temporales, aquellos que tienen bajos niveles de estudios, bajos salarios y se posicionan 
ideológicamente en el espectro político de derecha. Por el contrario, los individuos que están afiliados a los sindicatos y se posicionan en la izquierda política tienen actitudes algo más favorables a los derechos de los inmigrantes (Martín Artiles, Molina, 2011).

En segundo lugar (H2), la asociación entre modelos de bienestar y actitudes no es tan evidente como presuponíamos hipotéticamente: en un mismo modelo hay diferencias internas notables, como se ha demostrado en los casos de Escandinavia y los países del Mediterráneo. Por ello es más apropiado hablar de una asociación entre políticas de bienestar y actitudes: el gasto en protección social y las prestaciones por desempleo están correlacionados con la reducción de las desigualdades sociales y el riesgo de pobreza, lo que por ende coadyuva a la formación de actitudes favorables hacia la inmigración. Sin embargo, esta influencia sólo aparece de forma clara en el caso de Suecia y Noruega, no así en Dinamarca ni en Finlandia, lo que nos sugiere que la asociación de estas variables tiene más importancia en función de los países, de su historia, sus instituciones sociales, su política de inmigración y de asilo, que del modelo de bienestar propiamente dicho. El caso del Reino Unido es una muestra de ello: las actitudes hacia la inmigración son restrictivas y la protección social es débil, pero en cambio dicho país tiene políticas antidiscriminatorias muy avanzadas, como hemos visto en el Índice Mipex. Otro extremo en las actitudes desfavorables y muy restrictivas hacia la inmigración lo representan Grecia y Hungría, países de nueva inmigración, con un mayor peso de partidos de extrema derecha. Pero con una débil protección social, bajas prestaciones por desempleo y bajo nivel de riqueza. El nivel de riqueza per cápita es también una variable importante en la explicación de las actitudes.

En tercer lugar (H3), la actitud desfavorable hacia el acceso de los inmigrantes a los derechos sociales pone de manifiesto la debilidad del "compromiso igualitario". Ello también se refleja en el acceso a los derechos participación política, derechos de ciudadanía y servicios de formación y educación. La ciudadanía europea muestra una resistencia a la redistribución interétnica. La fragmentación racial y étnica propicia recelo, insolidaridad y el auge de movimientos nacionalistas excluyentes. La creciente heterogeneidad de la fuerza de trabajo contribuye a la segmentación y flexibilización del mercado de trabajo: los inmigrantes de terceros países no europeos prestan una importante movilidad circular en y entre los mercados de trabajo en la UE, lo que concuerda con el proyecto de la libre circulación de trabajadores, el desarrollo de las políticas neoliberales y la reorientación de las políticas de "welfare" hacia el "workafare".

En suma, la heterogeneidad étnica y racial tienden a dificultar la identificación entre la clase trabajadora, la afiliación sindical y la formación de coaliciones políticas valedoras de la defensa del Estado del Bienestar, lo que hemos denominado como el "dilema americano" (Schrieup, et. al, 2006; Banting; Kymlicka, 2008, entre otros). La respuesta a este problema lo constituyen las políticas de integración, la regulación del flujo inmigratorio, así como la participación sindical y política de los inmigrantes. El empoderamiento y el derecho de votación política de los inmigrantes es importante para su integración social, pero también para sostener las coalicio- 
nes políticas valedoras del Estado del Bienestar. En breve, las cuestiones planteadas por Habermas (2000) cobran hoy especial sentido: ¿Es posible la solidaridad y la defensa del Modelo Social Europeo con una población multicultural, étnica y racialmente heterogénea? 


\section{Anexo: metodología}

En esta investigación hemos utilizado la Encuesta Social Europea. El tamaño de la muestra nunca ha sido menor de 1.500 personas por país participante. La ESE 2010 para los 17 países estudiados suman 34.469 entrevistas, un 4\% de los cuales son inmigrantes. La ESE proporciona un amplio conjunto de indicadores sobre valores, ideología, actitudes, situación laboral e ingresos económicos. El referente actitudinal y de comportamiento social y político está presente en todos los datos sobre cada país, lo que permite la comparación entre ellos.

\subsection{Variables independientes}

En primer lugar, hemos tomado como variables independientes individuales, el género, la edad, nivel de estudios, ingresos económicos, contrato situación laboral, además del posicionamiento ideológico. En segundo lugar, hemos incluido una serie de variables independientes externas concernientes al contexto. Estas son la tasa de desempleo, la tasa de inmigración, el nivel de desigualdad, riesgo de pobreza después de transferencias sociales, el Producto Interior Bruto, así como el gasto en protección social, gasto en desempleo y la tasa de sustitución salarial en las pensiones por desempleo a largo plazo (más de dos años). Estas variables proceden de Eurostat (2008 y 2010).

\subsection{Variable dependiente}

La ESE nos proporciona una variable indicativa de las actitudes relacionada estrechamente con la solidaridad y el "compromiso igualitario": “¿Cuando deberían acceder los inmigrantes a los derechos sociales y a los servicios públicos?". Esta variable figura sólo en la encuesta de la ESE del 2008, no figura en la del 2010. La segunda variable dependiente analizada se r efiere a la "entrada de inmigrantes procedente de países pobres de fuera de Europa", lo que connota competencia por los recursos de empleo. Esta variable está recogida en la ESE del año 2010 y facilitar captar la tendencia restrictiva registrada entre los años 2002 y 2010, que ya hemos observado con la anterior variable relativa al "compromiso igualitario".

Además nos hemos apoyado en el análisis de otras dos variables: una, para captar la valoración de la opinión pública sobre la contribución de la inmigración a la economía (mediante una escala de 1 a 6 , donde es $1=$ mala y $6=$ buena), otra, para captar la valoración sobre la contribución de la inmigración al bienestar (mediante una escala de 0 a 10 , donde $0=$ "reciben más de lo que aportan" y $10=$ "reciben menos de lo que aportan"). 


\begin{tabular}{|c|c|c|c|c|}
\hline \multirow[b]{3}{*}{ Intersección } & \multicolumn{2}{|c|}{$\begin{array}{c}\text { Acceso a los derechos } \\
\text { inmediatamente }\end{array}$} & \multicolumn{2}{|c|}{$\begin{array}{c}\text { Nunca deberían acceder a los } \\
\text { derechos }\end{array}$} \\
\hline & B & $\operatorname{Exp}(B)$ & B & $\operatorname{Exp}(B)$ \\
\hline &,$- 609 * *$ & & $-3,114 * * *$ & \\
\hline Hombre & 0,051 & 1,053 & 0,105 & 1,111 \\
\hline Mujer & $0^{b}$ & . & $0^{\mathrm{b}}$ & . \\
\hline Edad 16-24 años &, $467 * * *$ & 1,596 & $-0,254$ & 0,776 \\
\hline 25-44 años &, $362 * * *$ & 1,436 & 0,078 & 1,081 \\
\hline $45-54$ ños &, $225 * *$ & 1,252 & ,198* & 1,218 \\
\hline 55-64 años &, $204 * * * *$ & 1,227 & 0,048 & 1,049 \\
\hline Más 65 años & $0^{\mathrm{b}}$ & 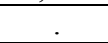 & $0^{\mathrm{b}}$ & the \\
\hline Estudios primarios &,$- 763 * * *$ & 0,466 &, $927 * * *$ & 2,526 \\
\hline Secundarios &,$- 595 * * *$ & 0,552 &, $837 * * *$ & 2,309 \\
\hline Universitarios & $0^{\mathrm{b}}$ & . & $0^{\mathrm{b}}$ & (2x) \\
\hline Contrato estable & 0,03 & 1,03 &,$- 321 * *$ & 0,726 \\
\hline Contrato Temporal & 0,192 & 1,211 & $-0,21$ & 0,81 \\
\hline Sin contrato & $0^{\mathrm{b}}$ & , & $0^{\mathrm{b}}$ & 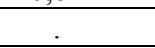 \\
\hline Desempleado & 0,043 & 1,044 & $-0,265$ & 0,767 \\
\hline Empleado & $0^{\mathrm{b}}$ & & $0^{\mathrm{b}}$ & \\
\hline Ingresos 1er quintil & $-0,098$ & 0,907 &, $838 * * *$ & 2,312 \\
\hline Ingresos 2er quintil & $-0,105$ & 0,9 &, $615 * * *$ & 1,85 \\
\hline Ingresos 3er quintil & 0,097 & 1,102 &, $387 * * *$ & 1,473 \\
\hline Ingresos 4er quintil & 0,133 & 1,143 & 0,152 & 1,164 \\
\hline Ingresos 5er quintil & $0^{\mathrm{b}}$ & & $0^{\mathrm{b}}$ & 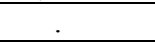 \\
\hline Derecha/Izquierda &,$- 173 * * *$ & 0,841 & 0,08 & 1,083 \\
\hline $\mathrm{N}$ & 34469,9839 & & & \\
\hline Pseudo R cuadrado & 0,056 & & & \\
\hline$-2 \mathrm{LL}$ & 17758,455 & & & \\
\hline
\end{tabular}




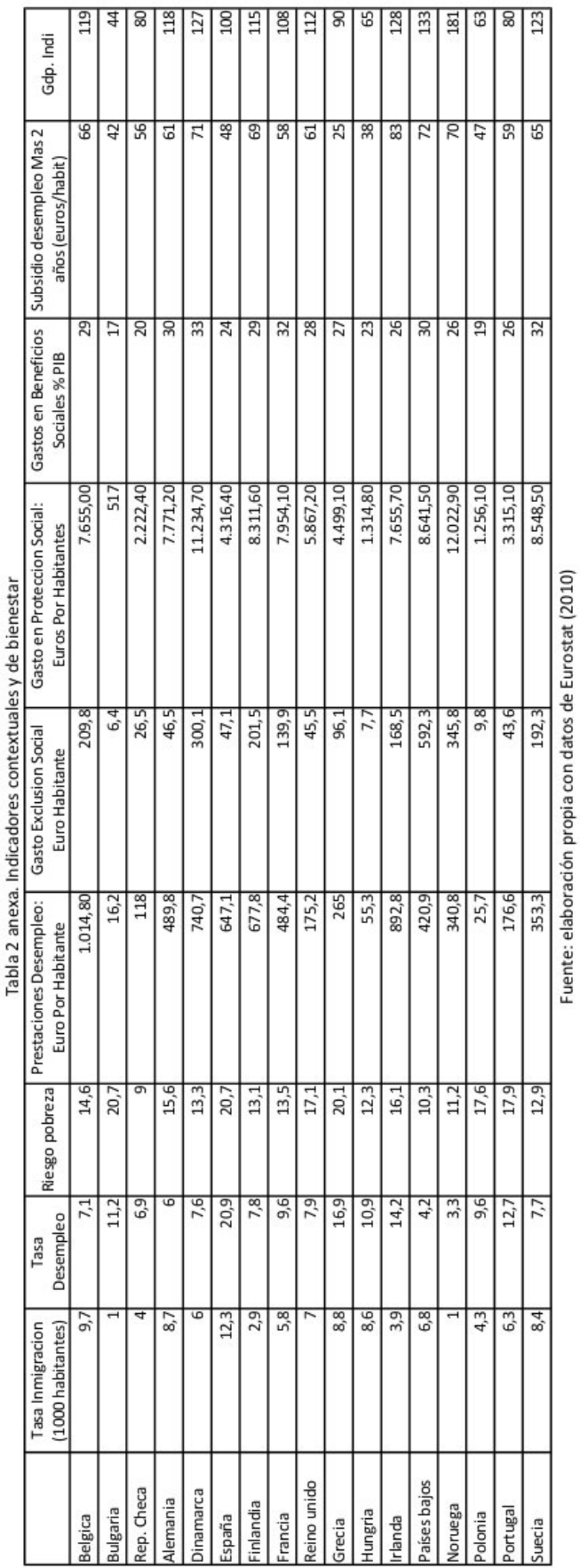




\section{Bibliografía}

AGENCIA DE LOS DERECHOS FUNDAMENTALES DE LA UE (2011): Manual de legislación europea contra la discriminación. Madrid:

http://www.oberaxe.es/files/datos/4eb3e55ad296b/normativa\%20FRA.pdf, consultado en 15 diciembre 2011

Balch, A. (2010). "Economic Migration and the Politics of Hospitality in Spain: Ideas and Policy Change", vol.38, $\mathrm{n}^{\circ}$ 5, pp-1037-1064

Banting, K.; Kymilcka, W. (2008). "Do multiculturalism policies erode the welfare state?" En LEIBFRIED, S.; M AU, S. Welfare State: Construction, deconstrustrucion, reconstruction. London: Edward Eldgar

Cachón, L. (2008). "La integración de y con los inmigrantes en España: debates teóricos, políticas y diversidad territorial." Política y Sociedad, vol. 45, 1, pp 205-235

Castles, S. (2006). "Guest workers in Europe: A resurrection? International Migration Review, volume 40, 4, pp.741-766

Card, D.; Dustmann, C.; Prestón, I. (2005). "Understanding attitudes to immigration: The migration and minority module of the first European Social Survey." Working Paper, $\mathrm{n}^{\circ}$ 5. London: CREAM (Centre for Research and Analysis of Migration).

Cea D'ancona, M.A.; Vallés, M.S. (2010). Evolución del racismo y la xenofobia en España. Informe 2010. Ministerio de Trabajo e Inmigración, http://www.mtin.es, consultado 10 noviembre 2011

Ceobeanu, A.M.; Escandell, X. (2010). "Comparative Analysis of Public Attitudes Towards Immigration and Immigration Using Multinational Survey Data: A Review of Theories and Research. Annual Review of Sociology, 36: 309-28.

Citrin, J.; Green, D.P.; Muste, C.; Wong, C. (2005). "Public opinion towards immigration reform: The role of economic motivation." The Journal of Politics, vol. $59, \mathrm{n}^{\circ} 3$, pp. 858-870

COMISION EUROPEA (2003). Comunicación de la Comisión al Consejo, al Parlamento Europeo, al Comité Económico y Social Europeo y al Comité de las Regiones sobre inmigración, integración y empleo. Bruselas (COM, 2003, 336 final.

EUROPEAN COMMISSION (2007). Towards a common immigration policy. Luxemburg, COM (2007), 628 final

EUROPEAN COMMISSION (2008). The labour market situation and impact for recent country migrants. [EU: Employment in Europe. Brussels: European Commission.]

Esping-Andersen, G. (2000). Los fundamentos sociales de las economías postindustriales. Barcelona: Ariel.

Feltzer, J.S. (2011). The evolution of Public attitude toward Immigration in Europe and the United States, 2000-2010. Florence: European University Institute. 
Ferrara, M. (2005). The Boundaries of Welfare. Oxford: Oxford University Press.

Gouveia, V.; Ros, M. (2000). "Hofstede and Schwartz's model for classifying individualism at the cultural level: their relation to macro-social and macroeconomic variables. "Psicothema, vol.12, Supl., pp.25-33

Gonzalez, M. (2008) Los sindicatos ante la inmigración. Madrid: Observatorio Permanente de la Inmigración

Habermas, J. (2000). La constelación postnacional. Barcelona: Paidós

Innerarity, C.; Acha, B. (2010). "Los discursos sobre ciudadanía e inmigración en Europea: Universalismo, extremismo y educación.” Revista Política y Sociedad, vol. 47, no 2, pp.63-84

Magnusson, L.; Jorgensen, J.; Dolvik, J. E. (2008). The Nordic approach to growth and welfare. Brussels: European Trade Union Institute

Martin Artiles, A.; Molina, O. (2011). "Crisis, economic uncertainty and unions members' attitude towards immigration in Europe." Transfer, Vol.17, $\mathrm{n}^{\mathrm{o}} 4$, pp. 453,470

Mayda, A.M. (2006). "Who is Against Immigration?" Review of Economic and Statistics, August 88 (2006), pp.510-530

Mau, S.; Burkhardt, C. (2009). "Migration and welfare state solidarity in Western Europe." Journal of European Social Policy, 19; 213

Menz, G. (2005). Varieties of Capitalism and Europeanization. Oxford: Oxford University Press.

Menz, G. (2008). "Migration and the Welfare State". In C. Parsons and T. Smeeding (eds) Immigration and the Transformation of Europe. Cambridge: Cambridge University Press.

Miguélez, F.; Recio, A. (2008). "Spain: large-scale regularisation and its impacts on labour market and social policy." Transfer Review, vol 14, n 2, pp. 589-606

Mipex (2010). Migrant Integration Policy Index III. London: British Council, http://www.mipex.eu, consultado el 25 de Julio 2012.

Moreno, F.J. (2007). "Inmigración y Estado del Bienestar." Política y Sociedad. Vol.44, $\mathrm{n}^{\circ} 2$.

Moreno, A. (2010). "Family and gender roles in Spain from a comparative perspective". European Societies, vol. 12, $\mathrm{n}^{\mathrm{o}}, 1, \mathrm{pp} .85-112$

Morissens, A. (2008). "Immigrants, Unemployment and Europe's Varying Welfare Regimes". In C. Parsons and T. Smeeding (eds) Immigration and the Transformation of Europe. Cambridge: Cambridge University Press

Pajares, M.; Jubuny, O. (2011). Sindicatos e inmigración, 1990-2010. Barcelona: Icaria

Rink, N.; Phalet, K.; Swyegedouw, M. (2009). "The effect of Immigrants Populations Size, Unemployment and Individual Characteristics on voting for the Vlaams Blok in Flanders, 1991-1999". European Sociological Review, vol. 25, $\mathrm{n}^{\mathrm{o}} 4,414-424$

Reyneri, E. (2006). "De la economía sumergida a la devaluación profesional: nivel educativo e inserción en el mercado de trabajo de los inmigrantes en Italia." REIS, $\mathrm{n}^{\circ} 116$, pp. 215-235. 
Rodriguez Monter, M. (2009). "Los valores culturales y el fenómeno de las migraciones internacionales." Athenea Digital, $\mathrm{n}^{\circ} 15,217-228$

Sarasa, S: (1995). "La sociedad civil en la Europa del sur. Una perspectiva comparada de las relaciones entre Estado y asociaciones altruistas." En Sarasa, S.; Moreno, L. El Estado del Bienestar en la Europa del Sur. Madrid: CIS, pp.156-186

Saxton, G.D.; Benson, M.A. (2003). "The Origins of Socially and Politically Hostile Attitudes towards Immigrants and Outgroups: Economics, Ideology or National Context?". The Journal of Political Science, vol, 31: 101-137

Schierup, C-U.; Hansen, P.; Castles, S. (2006). Migration, citenzeship, and the European Welfare State. Oxford: Oxford University Press

Schwartz, S.H. (2007). "Universalism Values and Inclusiveness of Our Moral Universe". Journal of Cross-cultural Psychology, $\mathrm{N}^{\mathrm{o}}$ 37:711. DOI $10.1177 / 0022022107308922$

Schwartz, S.H. (2011). "A p roposal for Measuring Value Orientation across Nations."

European

Social

vey, http://www.europeansocialsurvey.org/index.php?option=com_docman\&tas $\mathrm{k}=$ doc_view\&gid=126\&Itemid=80, consultado 3 Julio 2011.

Zapata-Barrero, E. (2000). "Política de inmigración y Unión Europea". Claves de Razón Práctica, $\mathrm{n}^{\circ}$ 104, pp.26-32

Zapata-Barrero, R. (2001). "Fundamentalismo estatal de la UE en torno a la inmigración." Revista CIDOB d'afers Internacionals, $\mathrm{n}^{\circ}$ 53, pp.149-176 